\title{
Energy storage systems for frequency stability enhancement in small-isolated power systems
}

\author{
I. Egido, L. Sigrist, E. Lobato and L. Rouco \\ Universidad Pontificia Comillas \\ Alberto Aguilera, 23, 28015 Madrid, Spain \\ A. Barrado, P. Fontela and J. Magriñá \\ Endesa \\ Ribera del Loira, 60, 28042 Madrid, Spain
}

\begin{abstract}
Frequency stability is one of the most relevant issues in operation of small isolated power systems. High penetration of renewals may significantly affect frequency stability of isolated power systems since renewable energy sources connected to the grid through power electronic interfaces do not provide either inertia or primary frequency regulation. This paper describes a research and demonstration project led by Endesa aimed at testing the state of the art of energy storage systems in isolated power system. Power systems of the Spanish Canary Islands will be used as test bench. The paper shows the contribution of La Palma ultra-capacitor and La Gomera flywheel to frequency stability and control enhancement.
\end{abstract}

Keywords. Isolated power systems, Energy storage systems, Frequency stability

\section{Introduction}

The most relevant issue in operation of isolated power systems is frequency stability [1]. Frequency stability is concerned with the ability of the generators to supply the loads within acceptable frequency ranges in case of generator tripping. Frequency stability is governed by the kinetic energy stored in the generator-prime mover rotating masses and the prime mover frequency primary regulation. If frequency excursions are not within $+/-2.5$ $\mathrm{Hz}$ range (see [2]), cascade tripping of the remaining generators can occur because of generator over/under frequency protections tripping.

High penetration of renewals may significantly affect frequency stability of isolated power systems since renewable energy sources connected to the grid through power electronic interfaces (wind and solar photovoltaic generation) provide neither inertia nor primary frequency regulation ([4]-[6]). The lack of inertia results in higher rate of change of frequency which requires faster and larger primary frequency regulation reserves to prevent frequency being outside $+/-2.5 \mathrm{~Hz}$ range.

Endesa is leading a research and demonstration project (STORE) on testing the state of the art of energy storage systems for several applications (peak-shaving, voltage control, frequency control) in small isolated power systems [8]. Power systems of the Spanish Canary Islands are used as test bench.
STORE project comprises three energy storage systems of different technologies: a 4 MW - 20 MWs ultracapacitor bank installed in La Palma power system, a 500 kW-18 MWs flywheel installed in La Gomera power system and a $1 \mathrm{MW} / 3 \mathrm{MWh}$ Li-ion battery installed in Gran Canaria system. Gran Canaria battery is aimed at providing peak shaving and voltage control services. Both La Palma ultra-capacitor and La Gomera flywheel are aimed at frequency stability enhancement. Actual records will show the contributions of La Palma and La Gomera systems.

\section{Isolated Power Systems}

Isolated power systems and interconnected power systems exhibit different features. Isolated systems are smaller than interconnected systems (like Continental Europe, Eastern North America and Western North America) and they cannot count with the support of the neighbour systems. Isolated power system can be of different size. Large isolated power systems are those of Argentina, Britain, Ireland, Japan and Korea. A very good example of small isolated power systems are those of Spanish Canary Islands. Table I summarizes the relevant features of the systems of Spanish Canary Islands.

\begin{tabular}{lrrr}
\multicolumn{4}{c}{ Table I: Features of the systems of Spanish Canary Islands. } \\
\hline & $\begin{array}{r}\text { Electrictity } \\
\text { generation } \\
\text { (GWh) }\end{array}$ & $\begin{array}{r}\text { Installed } \\
\text { capacity } \\
\text { (MW) }\end{array}$ & $\begin{array}{c}\text { Peak } \\
\text { demand } \\
\text { (MW) }\end{array}$ \\
\hline Tenerife & 3625 & 1084,28 & 593 \\
Gran Canaria & 3653 & 1111,8 & 598 \\
Lanzarote-Fuerteventura & 1458,7 & 377,97 & 256,5 \\
La Palma & 254,8 & 105,52 & 48,4 \\
La Gomera & 66,7 & 20,1 & 12,1 \\
El Hierro & 35,7 & 11,31 & 7 \\
\hline \hline
\end{tabular}

Operation of small isolated power systems is challenged by frequency stability and control since generation loss due to a generator tripping is generally a great fraction of the total generation. Load-shedding is needed to prevent the system collapse. Systems of the Spanish Canary Islands will be used as test bench to validate the contribution of energy storage systems to frequency stability enhancement.

\section{Frequency Stability}

Power system stability is concerned with the ability of the generators to run in synchronism and to supply the 
loads at acceptable frequency and voltage ranges in case of normal (load variations) and abnormal disturbances (faults, generator tripping) that may occur in power systems. The power system stability problem is a very difficult one. Its study is facilitated by separating it into three subproblems: angle, frequency and voltage stability [9]. Frequency stability will be present in all isolated power systems not matter how strong the power network is.

Precisely, frequency stability analyzes the capability of generators to supply load at acceptable frequency ranges in case of generator tripping ([11]-[13]). Frequency results from the generator rotor speeds. Generator rotor speeds result from the equilibrium between the power supplied by their primer movers (either turbines or engines) and the power consumed by the loads. Frequency stability is governed by the inertia of the rotating masses of primer movers and generators and the gain and time constant of the primary frequency regulation of prime movers in such a way that:

- After a generator trips, frequency decays with a rate of change that depends of the inertia of prime movergenerator rotating masses and the magnitude of the generation lost.

- Prime mover primary frequency regulation reacts to the frequency decay increasing the output of the power supplied by the prime movers.

- Frequency stabilizes if two conditions are fulfilled: the remaining on line generators have enough reserve to supply the generation lost and they are also able to increase the power output fast enough to avoid that frequency is below the settings of generator underfrequency protections to avoid generator cascade tripping.

Frequency stability is at risk in isolated power systems because of the fact that the frequency rate of change in case of generator tripping is bigger than in an interconnected power system. The inertia or the kinetic energy of the rotating masses of an interconnected system is much bigger than the inertia of the rotating masses of an isolated system. In addition of, the magnitude of the generation that can be tripped compared to the total rotating generation is much bigger in an isolated system than in an interconnected one.

Frequency stability can only be preserved by appropriate load-shedding schemes that disconnect fractions of the load to prevent the system collapse either in case of lack of reserve or in case of extreme disturbances. Loadshedding schemes are commanded by underfrequency and rate of change of frequency protections.

\section{Energy Storage Systems}

Storage of electric energy has been sought since the beginning of the development of electric power systems to overcome the technical problems and over-costs that result from the non-storageable nature of electric energy and the time variation of the load.
Pumped storage power plants have been the only practical solutions for massive (long term) storage. Pumped storage power plants have been incorporated to power systems for many years due to two main reasons:

- To optimize the operation of thermal based generation systems taking into account the constraints of nuclear and thermal power stations.

- To avoid spillage in hydro systems.

Pumped storage power plants can also provide system ancilliary services such as:

- Active power-frequency control.

- Reactive power-voltage control.

- Black-start.

The development of pumped storage power plants stopped due to the lack of affordable sites and gains in flexibility of power generation and the opportunities of demand side management actions. The increasing penetration of intermittent energy sources is motivating again the development of energy storage systems. Long-, medium- and short-term energy storage systems are being explored: The long-term energy storage systems under investigation are:

- compressed air

- power to gas

Medium-term energy storage systems under investigation are batteries of different technologies (Li-ion, NaS). The short-term energy storage systems under investigation are:

- Ultra-capacitors

- Flywheels

IEC White Paper on Electrical Energy Storage provides an excellent overview [7] of the state of the art and the applications. Figure 1, borrowed from [7], maps the energy storage technologies in a plane power-stored energy.

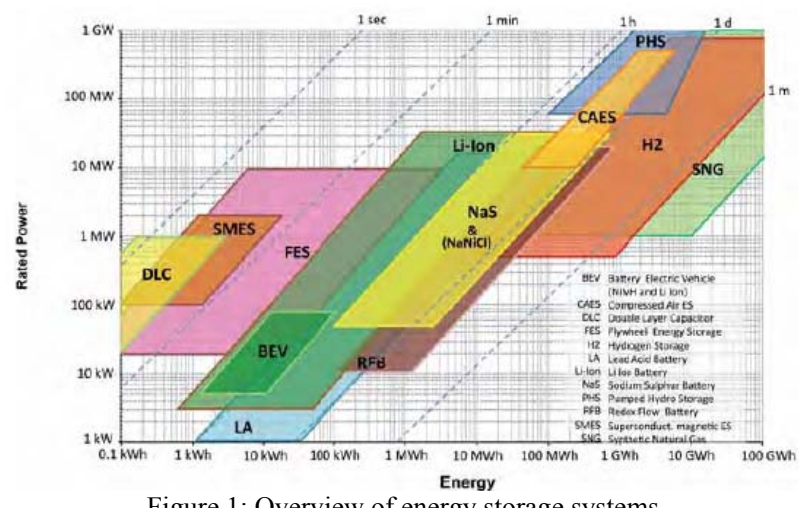

Figure 1: Overview of energy storage systems.

The main application of medium-term energy storage is peak-shaving for congestion management in subtransmission and distribution grids ([14], [15]). Thanks to the power electronic interface with the grid, 
medium- and short-term energy storage systems can provide fast response active power-frequency and reactive power-voltage control.

\section{STORE project}

STORE is a research and demonstration project led by Endesa aimed at testing several energy storage technologies and the feasibility of their application in isolated systems [8]. Endesa produces and distributes electric energy in the Spanish isolated power systems. Endesa seeks to determine the exact contribution of the technologies under investigation to each specific system. Moreover, Endesa wants to be aware of all integration and operational issues that may affect the value of the contribution of each technology.

\subsection{Project components}

The three systems of STORE project are:

- An ultra-capacitor in La Palma system

- A flywheel in La Gomera system

- A Li-ion battery in Gran Canaria system

La Palma ultracapacitor is a $4 \mathrm{MW} \mathrm{/} 20 \mathrm{MWs}$ (5 s) energy storage system. La Palma ultracapacitor has been supplied by Ingeteam [16]. Figure 2 shows La Palma ultracapacitor installation. It is connected at $20 \mathrm{kV}$ bus of Guinchos power generating station. Figure 3 shows the transmission grid of La Palma and the location of Guinchos power generating station [17]. Figure 4 displays the block diagram representation of La Palma ultra-capacitor. The ultra-capacitor is connected to the MV grid through a power electronic converter and a $\mathrm{MV} / \mathrm{LV}$ transformer. The capacitance and voltage of the ultra-capacitor bank are respectively $55.55 \mathrm{~F}$ and 1080 Vdc. The power electronic converter is of VSC (Voltage Source Converter) type. Vector control of the power electronic converter allows for the independent control of active and reactive power supplied by system to the grid.

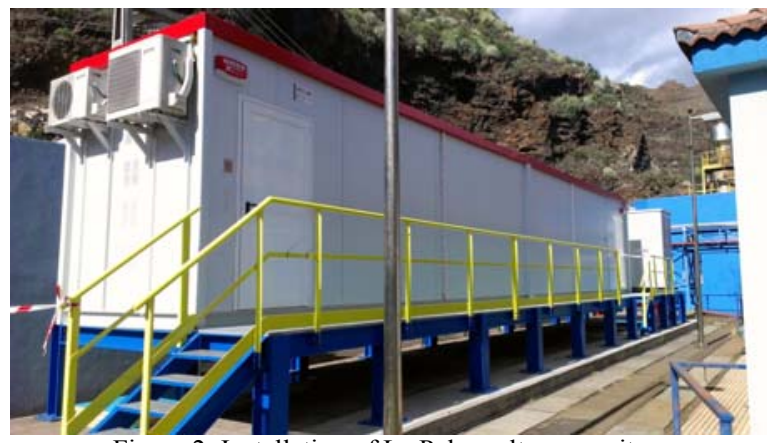

Figure 2: Installation of La Palma ultra-capacitor.

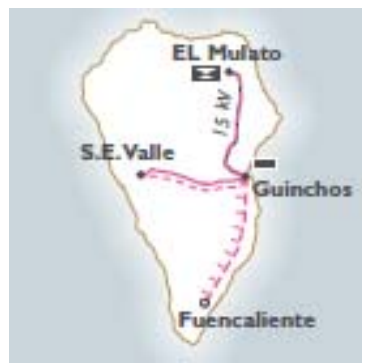

Figure 3: La Palma transmission grid.

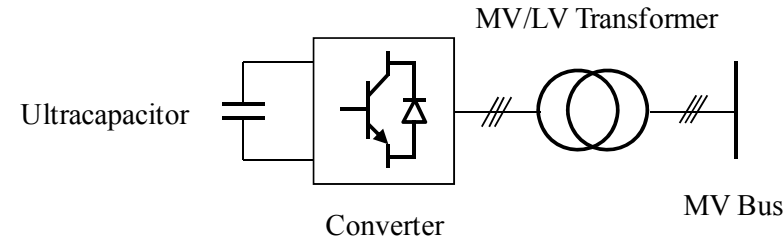

Figure 4: Block diagram representation of La Palma ultra-capacitor.

La Gomera flywheel is a $0.5 \mathrm{MW} / 18 \mathrm{MWs}$ (36 s) energy storage system. La Gomera flywheel was supplied by ABB-PowerCorp [18]. Figure 5 shows La Gomera flywheel installation. It is connected at Playa de Santiago $20 \mathrm{kV} / 400 \mathrm{~V}$ transformer station which is electrically close to Palmar power generating station. Figure 6 shows the transmission grid of La Gomera and the location of Palmar power generating station [17]. Figure 7 displays the block diagram representation of La Gomera flywheel. The flywheel which weights $3000 \mathrm{~kg}$ is driven by permanent magnet synchronous machine at a maximum speed of $3600 \mathrm{rpm}$. The machine is connected to the grid through two power electronic converters (grid side and machine side) coupled through a DC link capacitor. The power electronic converters are of VSC type. The grid side converter controls the reactive power supplied to the grid and the voltage of the DC link capacitor. The machine side converter controls the speed of the flywheel and thus the active power.

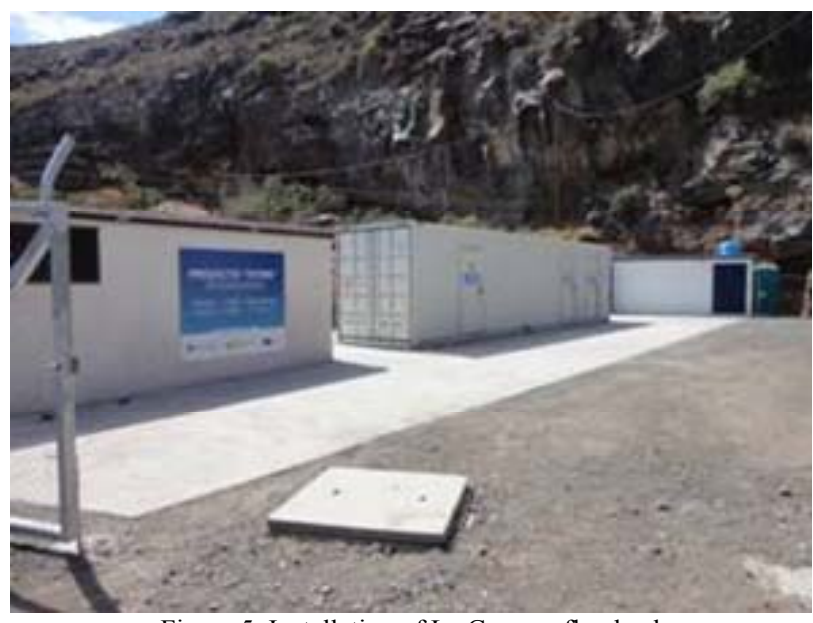

Figure 5: Installation of La Gomera flywheel

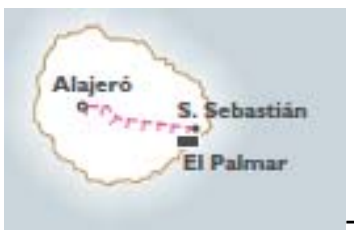

Figure 6: Transmission grid of La Gomera.

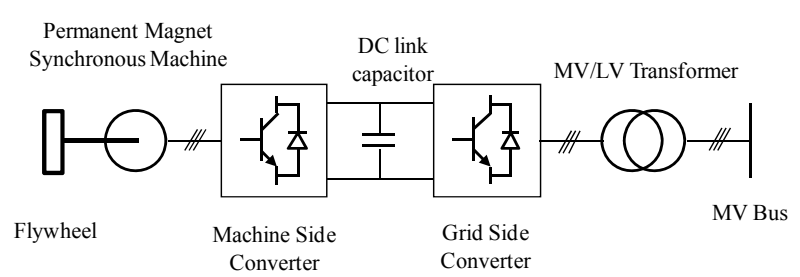

Figure 7: Block diagram representation of La Gomera flywheel. 
Gran Canaria Li-ion battery is a $1 \mathrm{MW} / 3 \mathrm{MWh}(3 \mathrm{~h})$ energy storage system. Gran Canaria battery was supplied by Saft Batteries [19]. Figure 8 shows Gran Canaria battery installation. It is connected at the end of a $20 \mathrm{kV}$ power line in La Aldea transformer station 20 $\mathrm{kV} / 400 \mathrm{~V}$. Figure 9 shows the transmission grid of Gran Canaria and the location of the future La Aldea $66 \mathrm{kV} /$ $20 \mathrm{kV}$ transformer substation [17]. It is planned the construction of a new $66 \mathrm{kV}$ power line to reinforce the power supply to La Aldea area. Figure 10 displays the block diagram representation of Gran Canaria battery. The grid connection scheme and of a battery is similar to the grid connection scheme of an ultra-capacitor. It must be noted that the ultra-capacitor and the battery energy storage systems share the primary control approaches [20].

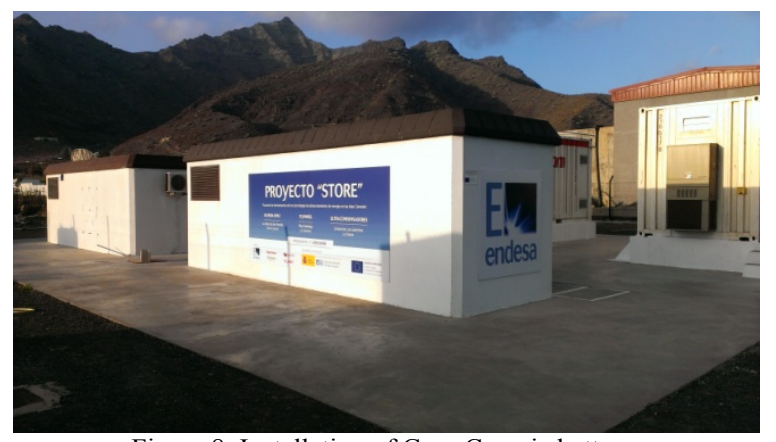

Figure 8: Installation of Gran Canaria battery.

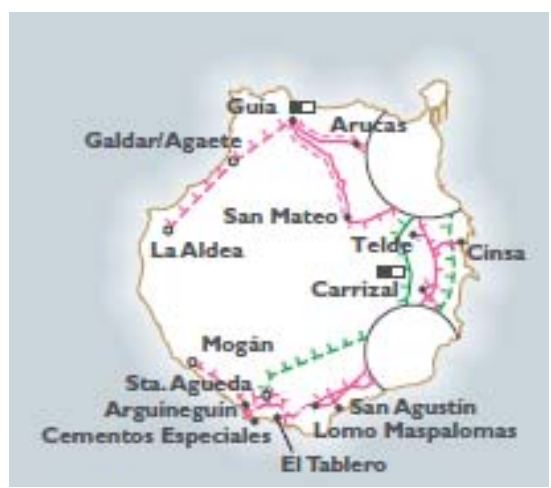

Figure 9: Gran Canaria transmission grid.

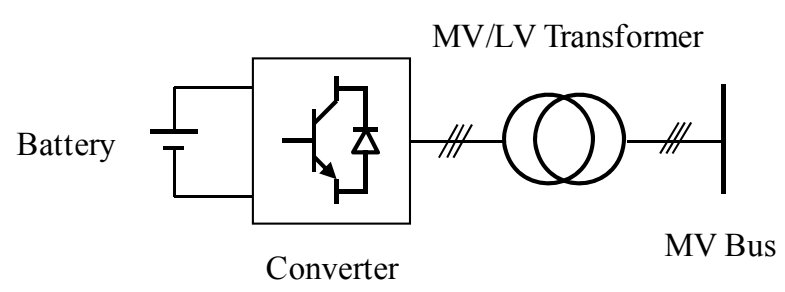

Figure 10: Block diagram representation of Gran Canaria battery.

It is very interesting (see Figure 11) to compare the power and stored energy of the STORE systems with the capabilities of an Endesa hydro pumped storage power plant in mainland Spain (Moralets, $200 \mathrm{MW}, 24 \mathrm{GWh})$. It should be noted that scales of $\mathrm{x}$ and $\mathrm{y}$ axis of Figure 11 are logarithmic.

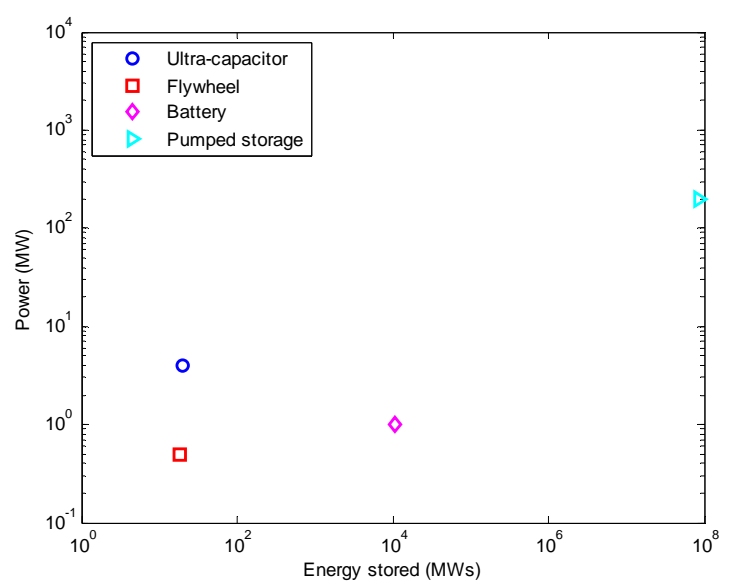

Figure 11: Comparison of the STORE systems with a hydro pumped storage power plant.

\subsection{Project approach}

To determine the exact contribution of the technologies under investigation to each specific system, the project has developed an approach that comprises three-phases:

- Phase 1: Power system studies

- Phase 2: Commissioning tests

- Phase 3: Follow-up activities

The first phase of project has undertaken power system studies to assess the impact of each energy storage system on the system dynamic response. It has required the development of appropriate simulation models of the energy storage systems to be used within industrial power system simulation package. The simulation model includes representations of the plant (power electronic converter and energy storage device) and the associated controllers (active power-frequency and reactive powervoltage). Simulations in case of a wide variety of disturbances were conducted to find the settings of the controllers. Moreover, the sizing and overall contribution of the system was confirmed.

The second phase of the project involved an exhaustive set of commissioning tests. Simulation models were validated firstly using open loop tests. Then, the settings obtained by simulation were tested in case of actual disturbances such as generator tripping. It must be take into consideration that system close loop response do not only depends on the energy storage system but also the overall power system.

The third phase of the project consists in following up the performance of each system in case of disturbances that occur in the system. The response in case of each disturbance is analyzed by comparing the actual response with simulation models output. It helps identifying improvements in parameter settings for maximizing the contribution of the energy storage system to the system performance. 


\section{Contribution to Enhancement of Frequency Stability}

This section provides examples of how La Palma ultracapacitor and La Gomera flywheel contribute to enhance frequency stability in their system. Control schemes are reviewed firstly to understand their performance [18].

La Palma ultra-capacitor independently controls active and reactive power as shown in Figure 12. Active power supply is constrained by the state of charge (SoC) of the ultra-capacitor. Active power-frequency controller commands the active power reference as shown in Figure 13. Active power-frequency controller incorporates two components: droop and inertia emulation components. Droop component is proportional to the frequency deviation and inertia emulation is proportional to the rate of change of frequency.

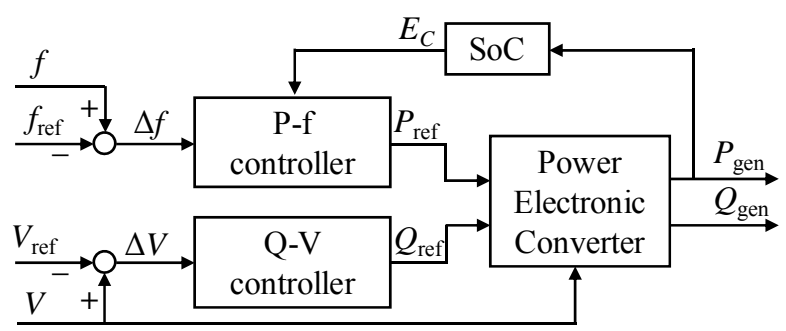

Figure 12: La Palma ultra-capacitor high-level model.

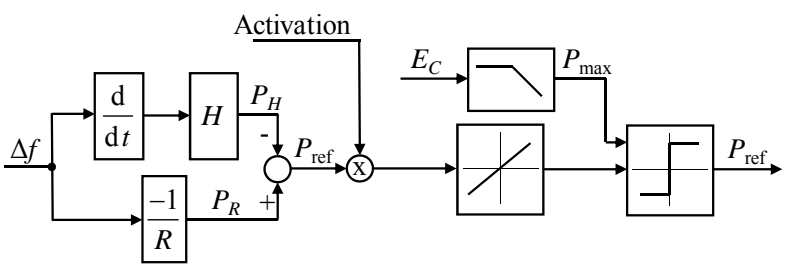

Figure 13: La Palma ultra-capacitor active power-frequency controller.

Figure 14 shows La Palma frequency and the ultracapacitor active power output variation in case of a 2.5 MW generator tripping in case that the ultra-capacitor does not react and in case of different settings of the frequency droop $(\mathrm{Kp}=1 / \mathrm{R})$. Figure 14 confirms the reduction of the frequency excursion and the ultracapacitor contribution to the frequency stability.
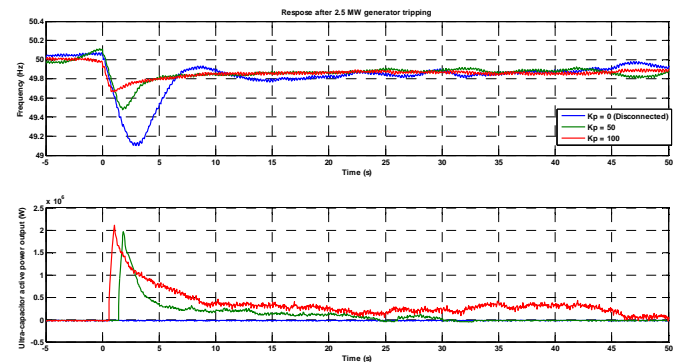

Figure 14: La Palma Ultracapacitor: La Palma frequency and the ultracapacitor active power output variation in case of $2.5 \mathrm{MW}$ generator tripping.

Figure 15 shows how La Gomera flywheel independently controls active and reactive current components. Active and reactive current components are constrained by the State of Charge (SoC) controller of the flywheel and the frequency, voltage and current limits. Figure 16 shows that active power-frequency controller commands the active current component. Active power-frequency controller incorporates two components: droop and inertia emulation components. Droop component is proportional to the frequency deviation and inertia emulation is proportional to the rate of change of frequency.

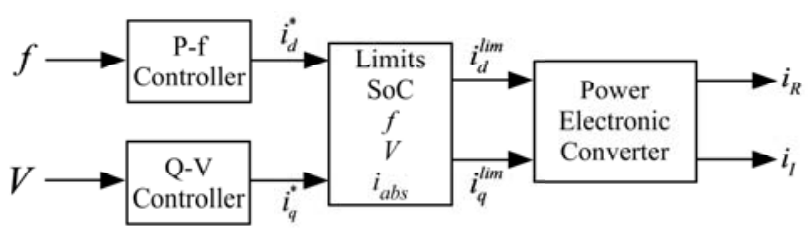

Figure 15: La Gomera flywheel high-level model.

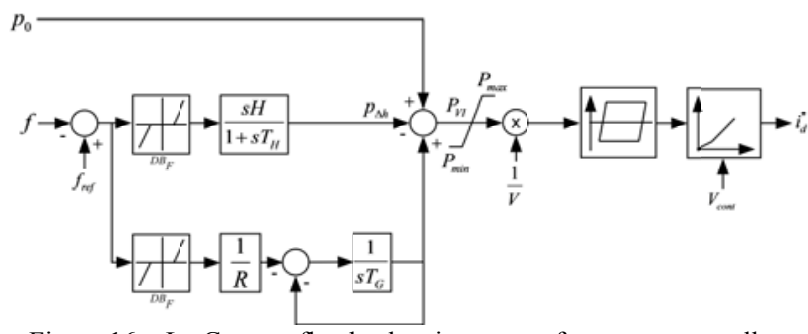

Figure 16: : La Gomera flywheel active power-frequency controller.

Figure 17 shows La Gomera frequency and the flywheel active power output variation in case of a $0.5 \mathrm{MW}$ generator tripping in case that the flywheel does not react and in case of different settings of the frequency droop $(\mathrm{Kp}=1 / \mathrm{R})$. Figure 17 confirms the reduction of the frequency excursion and the flywheel contribution to the frequency stability.
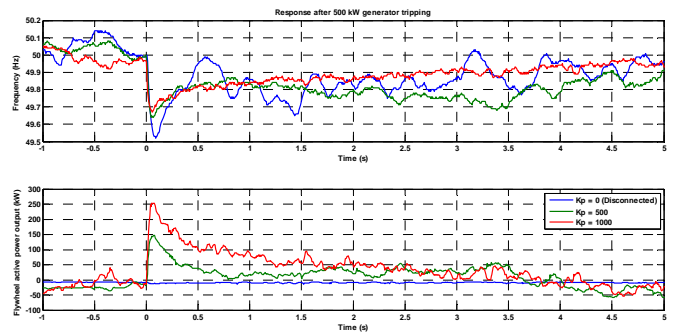

Figure 17: La Gomera Flywheel: La Gomera frequency and the flywheel active power output variation in case of a $500 \mathrm{~kW}$ generator tripping.

Energy storage systems can also contribute to primary frequency regulation. Of course it depends on the rating of the system compared to the rating of the on line generators. Figure 18 compares the system frequency and the flywheel active power output when the flywheel is not connected and when it is connected. The upper plot of Figure 18 shows how La Gomera flywheel improves the quality of primary frequency regulation. Frequency variation is smaller: almost half in the period shown. The lower plot of Figure 18 shows the flywheel active power output. The amount of active power required to improve the quality of the frequency regulation is less than $10 \%$ of the flywheel rated active power. 

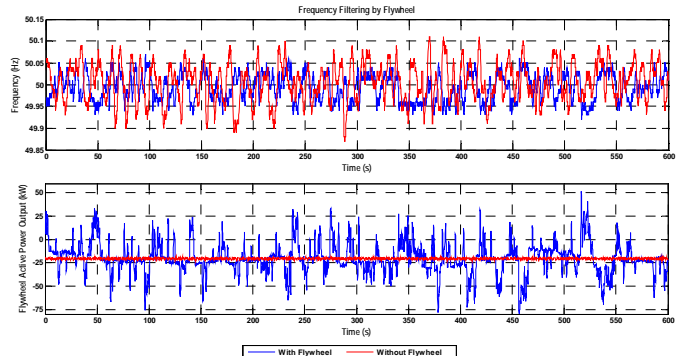

Figure 18: La Gomera Flywheel: Frequency control.

\section{Conclusions}

This paper has described a research and demonstration project led by Endesa aimed at testing the state of the art of energy storage systems in small isolated power systems. The project is testing three energy storage technologies: ultra-capacitors, flywheels and Li-ion batteries. Three power systems of the Spanish Canary Islands are being used as test bench. The paper has shown the contribution of La Palma ultra-capacitor and La Gomera flywheel to frequency stability and control enhancement.

\section{References}

[1] P. Centeno, F. Fernández, L. Rouco, M. González, J.M. Rojo, J.R. Diago, "Estabilidad de los sistemas eléctricos insulares", Anales de Mecánica y Electricidad, Vol. LXXXI, Fascículo IV, Julio Agosto 2004, pp. 33 - 40.

[2] ENTSO-E, "Continetal Europe Operation handbook", available at https://www.entsoe.eu/publications/system-operationsreports/operation-handbook/Pages/default.aspx.

[3] Red Eléctrica de España, "Procedimientos de Operación",

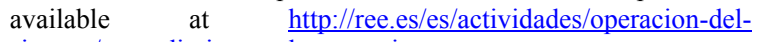
sistema/procedimientos-de-operacion.

[4] I. Egido, F. Fernández-Bernal, P. Centeno, L. Rouco, "Maximum Frequency Deviation Calculation in Small Isolated Power Systems", IEEE Transactions on Power Systems, Vol. 24, No. 4, pp. 1731-1738

[5] L. Rouco, J. L. Zamora, I. Egido, F. Fernández, "Impact of wind power generation on the frequency stability of synchronous generators". Cigré Session 2008, Paper No. A1-203, Paris, 24-29 Agosto 2008.

[6] I. Egido, L. Rouco, F. Fernández-Bernal, A. Rodríguez, J. Rupérez, F. Rodríguez-Bobada, S. Marín, "Máxima generación eólica en sistemas eléctricos aislados”, XII ERIAC (Encuentro Regional Iberoamericano de Cigré), Foz de Iguazú, 20-24 Mayo 2007.

[7] IEC White Paper, "Electrical Energy Storage", available at http://www.iec.ch/whitepaper/pdf/iecWP-energystorage-LRen.pdf.

[8] Endesa Press Release, available at http://www.endesa.com/ES/SALADEPRENSA/NOTICIAS/planta s-almacenamiento-electricidad-ProyectoSTORE.

[9] P. Kundur, "Power System Stability and Control", Mc Graw Hill, 1994.

[10] P. Kundur, J. Paserba, V. Ajjarapu, G. Andersson, A. Bose, C. Canizares, N. Hatziargyriou, D. Hill, A. Stankovic, C. Taylor, T. Van Cutsem, V. Vittal, "Definition and classification of power system stability IEEE/CIGRE joint task force on stability terms and definitions", IEEE Transactions on Power Systems, vol. 19, no. 3, 2004, pp. $1387-1401$.

[11] L. Sigrist, I. Egido, L. Rouco, "Performance analysis of UFLS schemes of small isolated power systems", IEEE Transactions on Power Systems, vol. 27, no. 3, pp. 1673-1680, August 2012.

[12] L. Sigrist, I. Egido, L. Rouco, "A method for the design of UFLS schemes of small isolated power systems", IEEE Transactions on Power Systems, vol. 27, no. 2, pp. 951-958, May 2012.

[13] L. Sigrist, I. Egido, L. Rouco, "Principles of a centralized UFLS scheme for small isolated power systems", IEEE Transactions on Power Systems, vol. 28, no. 2, pp. 1779-1786, May 2013.
[14] E. Lobato, L. Sigrist, L. Rouco, "Use of energy storage systems for peak shaving in the Spanish Canary Islands", 2013 IEEE Power and Energy Society General Meeting, Vancouver, Canada, 21-25 July 2013

[15] L. Sigrist, E. Lobato, L. Rouco, "Energy storage systems providing primary reserve and peak shaving in small isolated power systems: an economic assessment", International Journal of Electrical Power \& Energy Systems, vol. 53, pp. 675-683, December 2013.

[16] Ingeteam Brochure, "STORE Guinchos", available at http://www.ingeteam.com/Portals/0/Catalogo/Sector/Documento/ SSE 1419 Archivo cs24iptt00-a-pga-store-guinchos.pdf.

[17] Red Eléctrica de España, "Sistema eléctrico canario", available at http://ree.es/sites/default/files/diptico canarias.pdf

[18] PowerCorp,"PowerStore: Product Description and Data Sheet", available

http://www.abb.com/industries/db0003db004332/324a96c40c8eb 93ec1257a850040ebaf.aspx?productLanguage=es\&country=ES.

[19] Saft Batteries Brochure, "Saft Li-ion batteries helps Gran Canarias's STORE project to integrate renewable", available at http:/www.google.es/url?sa=t\&rct=j\&q=\&esrc=s\&source=web\&

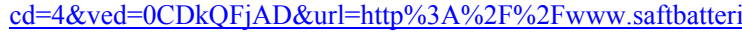
es.com\%2Fforce download\%2FEndesa.pdf\&ei=EW7jVMC4DM O8UZWYgogL\&usg=AFQjCNF5y0NodCXQqJC8MGNy8_8mVnsNQ\&bvm=bv.85970519,d.d24.

[20] L. Rouco, L. Sigrist, "Active and reactive power control of battery energy storage systems in weak grids", 2013 IREP Symposium on Bulk Power System Dynamics and Control - IX Optimization, Security and Control of the Emerging Power Grid - IREP 2013 Rethymno, Greece, 25 -30 August 2013.

[21] I. Egido, L. Sigrist, E. Lobato, L. Rouco, A. Barrado, “An ultracapacitor for frequency stability enhancement in small-isolated power systems: Models, simulation and field tests", Applied Energy, vol. 137, pp. 670-676, January 2015.

\section{Acknowledgements}

STORE is a demonstration project supported by the Spanish Ministry of Economy and Competitiveness through CDTI funds and the Technological Fund (EU FEDER Fund) lead by Endesa. Their support is gratefully acknowledged for their continuous support. 